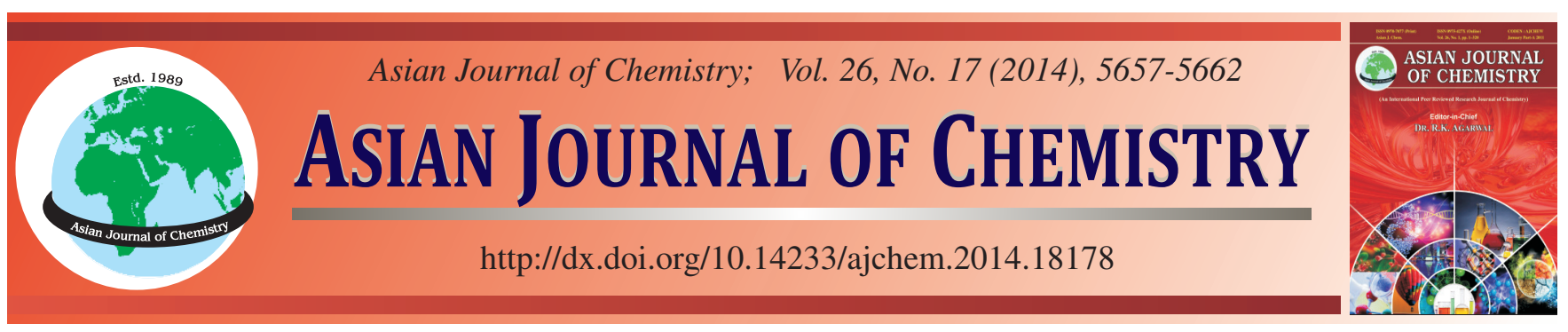

\title{
Microstructure and Tribological Properties of Graphite/Antimony Composites for Mechanical Seal $\uparrow$
}

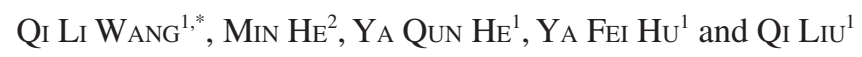

${ }^{1}$ Key Laboratory of Coal Processing and Efficient Utilization, Ministry of Education, School of Chemical Engineering and Technology, China University of Mining \& Technology, Xuzhou, P.R. China

${ }^{2}$ School of Mechanical \& Electrical Engineering, Xuzhou Institute of Technology, Xuzhou, P.R. China

*Corresponding author: Tel/Fax: +86 516 83995268; E-mail: wqlcumt@126.com

\begin{abstract}
Under the condition of $20 \mathrm{MPa}$ and $950^{\circ} \mathrm{C}$, by means of the mechanical pressure infiltration process, the molten antimony was forced into the micro pores of the porous graphite. The graphite/antimony composites were prepared to compare tribological properties with the three selected similar materials from Germany, USA and Japan, which represent the international advanced level. The microstructure of graphite/ antimony composites was analyzed by optical microscope and SEM. The tribological properties were also measured by friction and wear behaviour experiment. It was obtained that the density of home made graphite/antimony composites was $2.40 \mathrm{~g} / \mathrm{cm}^{3}$, the shore hardness (Hs) was 102.5, the compression strength was $285 \mathrm{MPa}$ and the flexural strength was $90 \mathrm{MPa}$. The homogeneous distribution of the metal phase promoted to form an optimal network structure in graphite/antimony composites and which is helpful to form a stable lubricating film and reduce the wear amount. The friction coefficients range from 0.12 to 0.14 , which is lower than the value of selected samples. The results showed that the physical properties and the tribological properties of the homemade graphite/antimony composites have taken a lead in the world.
\end{abstract}

Keywords: Graphite/antimony composites, Impregnation, Microstructure, Friction and wear.

\section{INTRODUCTION}

In the coal pulverizing system in thermal power plants, the Mill, as the rotating mechanical equipment under fast speed and overloading environment, is easy to cause pulverized coal leakage, which pollute the environment when they are floating in air as fine particles. Also, they can be easily breathed into the respiratory tracts of the workers, which will do harm to the health of the human being. The Mill in thermal power plant is treated as one of the places that are easily to exceed the standard in particulate matter (PM) 2.5 monitoring system. Therefore, solving the pulverized coal leakage is of great importance to promote environment protection as well as green production. Graphite materials are of heat resistance, wear resistance, low friction coefficient and thermal expansion coefficient as well as sound physical and stable chemical properties, which are all widely applied in the mechanical area. However, the graphite materials belong to porous materials, so there are many micro-pores in blanks, which reduce the antioxidant activity and mechanical strength, so people usually use impregnation technology to fill the graphite pores. Typically, the impregnated resin, copper, aluminum, silver, babbitt metal and other materials are used to fill the pores in graphite so as to make the pore structure dense, improving the density, intensity, antioxidant activity, friction wear and other performances, which scores some achievements ${ }^{1-7}$. One of the important applications is the rotator sealing of Mill, which is used to seal the pulverized coal and hard particles between rollers and the outer covers. In the early stage, the vacuum-pressure impregnating resin process is applied to densify the graphite materials. Put the blanks roasted into the impregnating tanks and then impregnate the liquid resin to the pores of graphite at the set temperature $\left(50-60{ }^{\circ} \mathrm{C}\right)$ and pressure $(0.8 \mathrm{MPa})$. The flexural strength and compression strength after impregnation are increased, but their increase of hardness is relatively small. The general performance of the resin impregnated is improved and the working life of sealing materials in Mill will between 5000-8000 $\mathrm{h}^{8}$.

In recent years, graphite/antimony composites, as the main sailing material in the Mill of thermal power plant, have been widely applied. Antimony/graphite sealing ring of Babcock in Germany has excellent self-lubricating performance, friction

$†$ Presented at 2014 Global Conference on Polymer and Composite Materials (PCM2014) held on 27-29 May 2014, Ningbo, P.R. China 
wear performance and high-temperature stability. Compared with the impregnated resin materials, the parameters and indexes have seen a large increase (Table-1) $)^{8,9}$. However, it is very difficult for the vacuum-pressure impregnating process to make antimony/graphite composites. There are two reasons: one is the high melting point of antimony $\left(631^{\circ} \mathrm{C}\right)$ and the high impregnating temperature $\left(800-1000^{\circ} \mathrm{C}\right)$, the other is the large surface tension of antimony in the molten state and the high impregnation resistance. Under the situation of high temperature and negative pressure, the mobility of molten antimony is hard to solve. It can be directly reflected that the impregnated depth of graphite materials is not enough and most impregnation is surrounded or just on the surface of the blanks, in which the metal phase is not evenly distributed and the friction coefficient is volatile.

Germany is one of the earliest countries to start the research of graphite/antimony composites and the density of their antimony/graphite composites can reach $2.3 \mathrm{~g} / \mathrm{cm}^{3}$, Shore hardness, 100 , flexural strength, $70 \mathrm{MPa}$ and the working life can reach 25000-30000 h. No matter in mechanical performance or friction wear performance, German products take the lead in the world ${ }^{9,10}$. At the same time, Japan and America have also conducted relevant research work and made a series of achievements. Their graphite/antimony composites are close to German products in some performance, which represents the world advanced level of graphite/antimony composites at present. China has also launched some relevant research work in improving the sealing materials of graphite/antimony composites domestically. Although some achievements have been made, there is still lag behind the advanced international level in terms of performance and working life. In this study, the mechanic compression molding method and high-pressure impregnation process was developed to produce the graphite/ antimony composites. Moreover, the mechanical properties and friction wear performance of the graphite/antimony composites were measured. The micro-structure is analyzed to compare with the similar composites with international advanced level, so as to improve the quality of Chinese graphite/ antimony products.

\section{EXPERIMENTAL}

Preparation of the antimony/graphite materials: The raw materials should be coke particles and the proportion of aggregate grain size distribution is: 50 \% 200-400 mesh; $30 \%$
400-600 mesh; $15 \%$ 600-800 mesh and $5 \%$ ultra-fine powders less than 1000 mesh. The medium temperature coal tar pitch is used as binders, which are ground to and added to aggregate grains. According to the quality proportion, the pitch content added should be $26 \%$ and then put into the rollers to knead for $4 \mathrm{~h}$. After the full mixture of aggregate grains and the binders, heat the mixture to $150-170{ }^{\circ} \mathrm{C}$ for $1 \mathrm{~h}$, keep it under the pressure of $35 \mathrm{MPa}$ for $5 \mathrm{~min}$ and make the blanks. Heat the metallic antimony in graphite crucible until it reaches the molten situation and put the blanks into the impregnating tank. Heat it to $950{ }^{\circ} \mathrm{C}$ until the graphite blanks begin to absorb heat and the micro pores open and expand. Then pour the molten antimony into impregnating tank. After being vacuumed, high pressure gas is used to compress, so the strong pressure forces the molten antimony to penetrate into the micro-porous structure of the blanks. It is needed to keep the impregnating pressure for $5 \mathrm{~min}$ at $20 \mathrm{MPa}$; then open the impregnating tank and separate the impregnated blanks and molten antimony before the molten antimony begins to solidify. Isolate the air from the impregnated antimony/graphite composites until it is cooled to the room temperature and then conduct the followup processing and treatment.

Comparative study of antimony/graphite composites between homemade samples and the samples of a (from Germany), b (from Japan), c (from America) is developed in terms of mechanical performance measurement, microstructure analysis and friction \& wear test. The universal material testing machine WJ-10B is used to test the mechanical properties of each sample. PG51 metallographic microscope is used to shoot the micro-structure of the materials. Quanta250 scanning electron microscope (SEM) and AN10000 Energy Disperse Spectroscopy (EDS) are used to shoot the porous structures of the materials so as to examine its major components and distribution. MW-1 friction-abrasion testing machine is used to conduct wear test in order to measure the friction and wear performance of graphite/antimony composites under dry friction.

\section{RESULTS AND DISCUSSION}

Physical properties of the materials: Table- 2 showed that the volume density of the four samples is very close. The differences of flexural strength and Shore hardness parameters are quite obvious. The comprehensive mechanical performance of sample a is the best and except the density is a little bit

\begin{tabular}{ccccccc}
\multicolumn{7}{c}{ TABLE-1 } \\
COMPARISON OF MATERIAL CHARACTERISTICS AND OPERATING LIFE OF SEALING RINGS ON MILLS
\end{tabular}

\begin{tabular}{|c|c|c|c|c|c|c|}
\hline \multicolumn{7}{|c|}{$\begin{array}{r}\text { TABLE-2 } \\
\text { PHYSICAL PROPERTIES OF GRAPHITH }\end{array}$} \\
\hline Sample & $\begin{array}{l}\text { Bulk density } \\
\left(\mathrm{g} / \mathrm{cm}^{3}\right)\end{array}$ & $\begin{array}{c}\text { Compression } \\
\text { strength }(\mathrm{MPa})\end{array}$ & $\begin{array}{l}\text { Flexural Strength } \\
\text { (MPa) }\end{array}$ & $\begin{array}{l}\text { Shore hardness } \\
\text { (Hs) }\end{array}$ & $\begin{array}{l}\text { Thermal expansion } \\
\text { coefficient } / 10^{-6}\left({ }^{\circ} \mathrm{C}\right)\end{array}$ & $\begin{array}{l}\text { Porosity } \\
(\%)\end{array}$ \\
\hline $\mathrm{a}$ & 2.35 & 300 & 91 & 104.5 & 3.6 & 0.68 \\
\hline $\mathrm{b}$ & 2.32 & 265 & 82 & 85 & 5.2 & 0.63 \\
\hline c & 2.35 & 275 & 88 & 93.5 & 4.8 & 0.91 \\
\hline d & 2.40 & 285 & 90 & 102.5 & 4.5 & 0.80 \\
\hline
\end{tabular}


lower than sample d, the rest parameters are all the best among all the samples. Especially from the perspective of sealing condition of the Mill, a high strength and a low expansion coefficient are the optimal. The compression strength of sample a reaches $300 \mathrm{MPa}$, Shore hardness is $104.5 \mathrm{Hs}$ and the thermal expansion coefficient is $3.6 \times 10^{-6} /{ }^{\circ} \mathrm{C}$. The density, strength and hardness of sample $b$ is the smallest one among the four samples, which are the shortages as the sealing materials for machines, but the open porosity is the smallest among the four, which means good dense situation. The open porosity of sample $\mathrm{c}$ is greater than sample a and sample b, but the density is higher than sample $b$ and lower than sample $d$. It indicates that the large size aggregate grain particles or the impregnated metal phase in the matrix have a large proportion, which increase the volume density. The comprehensive indexes of sample $\mathrm{d}$ are only next to sample a: it has the largest volume density among the four, which tells a large metal phase proportion and the strength, hardness, expansion coefficient and the open porosity are all better than sample $b$ and $c$.

Micro-structure and components of the materials: Fig. 1 shows the optical micrographs of the samples, from which we can observe the size composition and the distribution of the materials as well as the distribution of antimony. The white bright material in the figure is the impregnated metallic antimony and the common features of the four samples are the evenly distributed antimony, but four samples also show different distribution characteristics. Sample a has relatively large and coarse particles and the large particles do not gather and are evenly distributed. The metal phase of antimony is evenly distributed and shown as thin and long shape. On the other hand, the small particle and the binders can wrap the large aggregates well, leaving no obvious open pores.
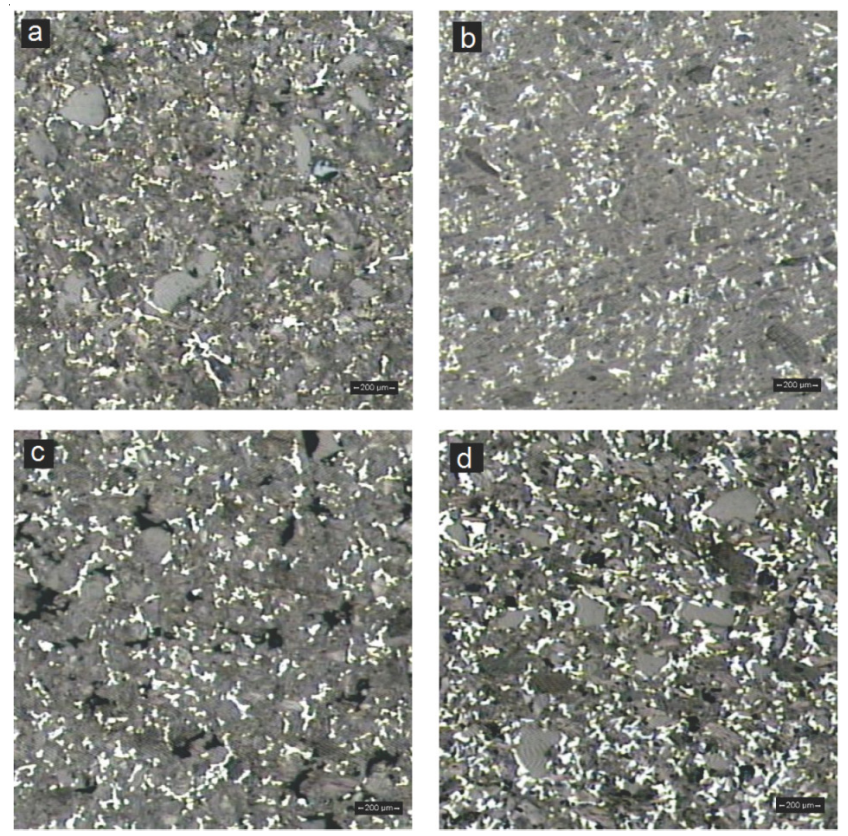

Fig. 1. Optical micrographs of the graphite/antimony composites

In sample b, the metal phase of antimony is soundly and evenly distributed. There is less antimony in large size particles and there is no large and coarse particle to be found in the matrix. Fines and ultra fine powders are the main contents, which influence its hardness and density. The roasting and impregnating effect is sound with fewer pores and holes that are not impregnated, so the porosity is low (Table-2). There are a number of large and coarse aggregates in sample $\mathrm{c}$ and there are many not impregnated holes between the aggregates. Moreover, the particle size of the metal phase for antimony is larger than sample $a$ and $b$. This is because that the capillary diameter in the porous structure for the blanks before impregnating is relatively large, so the capillary diameter is the same with the molten antimony after their holes are filled up. In sample d, it also contains a number of large and coarse aggregates and the pores without impregnation are less than sample c. Metallic antimony is more evenly and denser distributed. Moreover, a relatively network structure is formed and indicates that the long-distance connection of sample $d$ is the best of all. It is conducive to promote the molten antimony to penetrate into the porous structure, so the impregnation number is obviously higher that the other 3 samples. Therefore, it raises the volume density and hardness of the materials, same with the data in Table-2. The volume density of sample $d$ is the largest and its Shore hardness is also better than sample b and c.

In Fig. 2, the SEM morphologies show the micro porous structure, distribution of metallic antimony and the geometrical morphology of the sample. It can be seen that samples a and c have a large number of bulk metals and form local accumulation, which indicates that the pore channel in these areas have a good connection before impregnation. At the same time, it can be clearly seen that there are large and coarse aggregate particles and some holes that are not impregnated. In sample $\mathrm{b}$, there is almost no similar bulk aggregate particle. No matter for the matrix or the impregnated metal phase, they all have small particle size and less open pores and the matrixes are very smooth. In sample d, the distribution of metallic antimony is more even and almost fill the whole section. It indicates that the porous structure after roasting forms percolation network structure with long-distance connection and the molten antimony has a sound penetration during the impregnation process. The metallic antimony is shown in long and thin shape, which is conducive to maintain each physical properties of different position on the same contact area stable. Therefore, sample $\mathrm{d}$ has the best structure from this point of view.

In order to study the main components and distribution of the materials, one can get the main components of every sample by EDS analysis (Table-3) and the distribution of each element is shown in Fig. 3. It can be seen that the components of elements in every sample are close, mainly including Sb and $\mathrm{Si}$ and the secondary elements are $\mathrm{S}, \mathrm{Al}, \mathrm{Fe}$; less $\mathrm{Mg}$ is tested in sample b and sample d; and there are also less $\mathrm{Cu}$ and $\mathrm{K}$ in small quantity in sample b. The relevant content of antimony in sample $\mathrm{d}$ is the largest $(87 \%)$, which increases its volume density. Compared with sample a, the matrix material of sample d contains more holes without impregnation (the open porosity is $0.8 \%$, greater than $0.68 \%$ in sample a). The dense situation of sample $d$ is not as good as sample a, which influences its strength and hardness parameters, a little bit 


\begin{tabular}{cccc}
\hline & & TABLE-3 \\
& & \multicolumn{2}{c}{ COMPONENT ELEMENTS OF GRAPHITE/ANTIMONY COMPOSITES } \\
\hline Sample & Main elements & Minor elements & Relative content of elements \\
\hline a & Sb Si & Fe S & Sb: $78 \% ; \mathrm{Si}: 13.7 \% ; \mathrm{S}: 4.2 \% ; \mathrm{Fe}: 1.5 \%$ \\
$\mathrm{~b}$ & $\mathrm{Sb} \mathrm{Si} \mathrm{Al}$ & $\mathrm{Fe} \mathrm{K} \mathrm{Cu} \mathrm{Mg} \mathrm{S}$ & $\mathrm{Sb}: 72 \% ; \mathrm{Si}: 8.9 \% ; \mathrm{Al}: 8.1 \% ; \mathrm{S}: 5.1 \% ; \mathrm{Mg}: 1 \% ; \mathrm{K}: 1.6 \% ; \mathrm{Cu}: 1.1 \% ; \mathrm{Fe}: 1.1 \%$ \\
$\mathrm{c}$ & $\mathrm{Sb} \mathrm{Si}$ & $\mathrm{S} \mathrm{Al} \mathrm{Fe} \mathrm{K}$ & $\mathrm{Sb}: 72 \% ; \mathrm{Si}: 13.4 \% ; \mathrm{Al}: 5.74 \% ; \mathrm{S}: 6.51 \% ; \mathrm{K}: 2.34 \%$ \\
$\mathrm{~d}$ & $\mathrm{Sb} \mathrm{Si}$ & $\mathrm{S} \mathrm{Al} \mathrm{Mg} \mathrm{Fe}$ & $\mathrm{Sb}: 87 \% ; \mathrm{Si}: 4.9 \% ; \mathrm{Al}: 3.2 \% ; \mathrm{S}: 2.5 \% ; \mathrm{Mg}: 1.0 \% ; \mathrm{Fe}: 1.6 \%$ \\
\hline
\end{tabular}
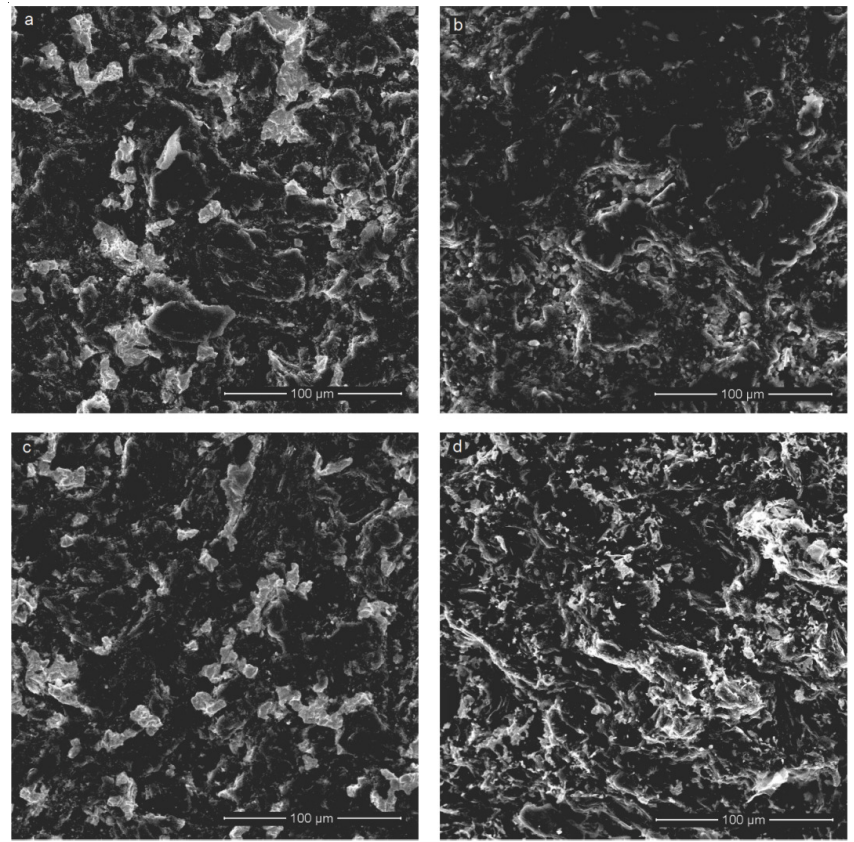

Fig. 2. SEM morphologies of surfaces of the graphite/antimony composites
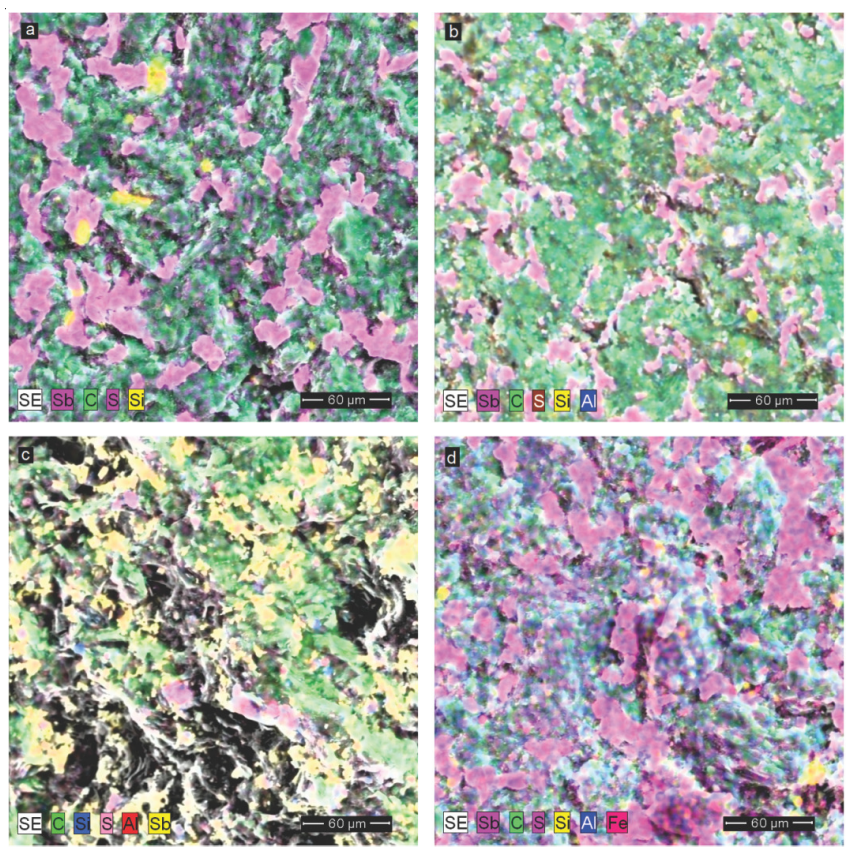

Fig. 3. Distribution of the elements in graphite/antimony composites from EDS analysis under the condition of high voltage is $20.0 \mathrm{KV}$, work distance is $20.60 \mathrm{~mm}$ and pulse is $5.63 \mathrm{kcps}$

lower than sample a. Sample a and sample c are tested to have more $\mathrm{Si}$, which is conducive to promote the graphitization process of carbon and solidify the solution strengthening of the matrix, increasing the wear resistance of the materials. Hu et al. ${ }^{9}$ reported that $\mathrm{Cu}, \mathrm{K}, \mathrm{Fe}$ and $\mathrm{Mg}$ do not have an obvious promoting role to impregnated antimony/graphite composites and they are usually regarded as impurities because of the low level in content.

Fig. 3 reflects the main components of every sample and their distribution in microstructure. matrix $\mathrm{C}$ is the main component of the material, which covers the entire section; the black area is the holes that are not impregnated. In sample a and sample $d$, the even distribution of antimony is better than sample b and c. Sample c has many holes without impregnation and they have a clear outline. In sample $b$, the elements are mainly composed of matrix $\mathrm{C}$ and the impregnated metal phase is relatively less. Moreover, there are fewer holes without impregnation. The surface of sample $b$ is flat without the clear level and outline as in sample c. Although sample b is tested with many types of elements, some elements as $\mathrm{Cu}, \mathrm{K}, \mathrm{Mg}$ and $\mathrm{Fe}$ are so few in content that they cannot be directly shown in Fig. 3(b).

Friction and wear performance of the materials: High strength, low expansion coefficient and automatic lubrication are the outstanding features of mechanical carbon/graphite materials, which display good wear resistance and low friction coefficient ${ }^{11-16}$ under the condition of dry friction, water lubrication and steam lubrication. Many scholars ${ }^{17-21}$ have carried out in-depth research on the tribological properties of carbon/ graphite, carbon/carbon and graphite/alloy materials under different friction pairs and different rotating speed and rich achievements have been resulted. The antimony graphite for the rotary seals in Mill is working under the condition of total dry friction, forming the friction pairs with the millstones of Mill. In order to compare the friction and wear performance of each sample, a friction and wear experiment is carried out on the universal material testing machine. The experiment conditions are as follows: the specification of the sample is $\varnothing 4$ $\times 10 \mathrm{~mm}$, the $45 \#$ steel test ring (the surface roughness is $R_{a}$ $0.52-0.70 \mu \mathrm{m}$ and hardness is $40-45 \mathrm{HRC}$ ), the rotary speed is $200 \mathrm{r} / \mathrm{min}$, the friction torque is $170-210 \mathrm{~N} . \mathrm{mm}$, the load is $100 \mathrm{~N}$, the testing temperature $\left({ }^{\circ} \mathrm{C}\right)$ is $207-217.8$, time is $0.5 \mathrm{~h}$, record every $5 \mathrm{~s}$, the sampling time is $5-1805 \mathrm{~s}$ and the weight of the samples is measured by an electronic balance with 0.01 mg precision.

Table-4 showed that the maximum friction coefficient is 0.185 , the minimum value is 0.119 and the mean friction coefficient ranges from 0.12 to 0.15 . The absolute wear loss and the friction coefficient of sample d are the smallest. On the other hand, the value of sample $\mathrm{c}$ is the largest. These are all related to the porous structure of every sample. The porous structure of sample b has a sound compactness and fewer holes, which are easy to form stable lubrication films. So the friction coefficient of sample $b$ is only next to sample $d$. The porous 
TABLE-4

RESULTS OF THE WEAR TEST OF THE SAMPLES

\begin{tabular}{cccccccc}
\hline \multirow{2}{*}{ Sample } & \multicolumn{2}{c}{ Weight of samples $(\mathrm{g})$} & \multicolumn{2}{c}{ Weight loss } & \multicolumn{3}{c}{ Friction coefficient } \\
\cline { 2 - 8 } & Before test & After test & Absolute $(\mathrm{g})$ & Relative $(\%)$ & Max. & Min. & Ave. \\
\hline a & 0.27135 & 0.27125 & 0.00010 & 0.0369 & 0.185 & 0.137 & 0.143 \\
b & 0.27268 & 0.27256 & 0.00012 & 0.0401 & 0.162 & 0.129 & 0.135 \\
c & 0.27332 & 0.27318 & 0.00014 & 0.0512 & 0.177 & 0.142 & 0.148 \\
d & 0.28865 & 0.28862 & 0.00003 & 0.0104 & 0.153 & 0.119 & 0.126 \\
\hline
\end{tabular}

structure of sample c is relatively worse, which has many large size particles and a number of holes without impregnation. Therefore it is not conducive to form a stable lubrication film with a large wear mass loss and large friction coefficient. The structure compactness of sample $d$ is good and the porous distribution is relatively even. So the impregnated antimony is evenly distributed with less wear mass loss, which is easy to form relatively stable lubrication films. Consequently, the friction coefficient is low.

For graphite materials, the density, hardness, compression strength and the particle diameters all can exert influence on its friction and wear performance. So the key issue is that whether the stable lubrication films can be established to realize the film lubrication during the wearing process ${ }^{22-25}$. In the initial stage, the seals of Mill are totally under dry friction with the low combining capacity of the plane layers in the graphitic crystalline. The graphite is easy to slide along the crystal face under a relatively shear stress, so the graphite with exfoliation has strong absorption capacity which will be absorbed to the grinding surface to form the graphite films. There are micropores between the metal phase and the matrix materials and physical absorption will appear under van der Waals force to absorb every gas molecule (e.g. water molecule). The vapor under natural condition will reduce the $\mathrm{C}-\mathrm{C}$ bond of the frictional surface, which will establish a layer of graphite-water film. The notable feature of the film is to make the graphite self-lubricating. On the other hand, in antimony/graphite composites, the thin film is formed by graphite film, water thin films and metal oxide film. It makes friction between the antimony/graphite composites and the grinding pairs conducted between lubricating layers. So the boundary friction is established, which reduces the adhesive wear of antimony phase and friction pair of 45\# steel ring as well as reducing the friction coefficient. If there are large diameter sized particles, there will be a large amount of wear loss during the wearing process and even are dropped off. The already formed lubrication film will be destroyed, so there is a quick data fluctuation of the friction coefficient ${ }^{9,26}$.

It can be seen from Fig. 4 that in the initial stage of wear, the weight loss is large and the friction coefficient is high. The friction coefficients of the four samples are 0.42, 0.27, 0.29 and 0.27 higher than their mean value, respectively. At the initial stage of wearing, the lubricating films quickly form a stage, in which the downward gravity of the friction coefficient reflects the speed of film forming process-the friction coefficients of every sample tends to be stable at $200 \mathrm{~s}$, forming the lubrication film. 5-200 s is the film fast forming stage; $200-1000 \mathrm{~s}$ is the stable wearing stage, in which the friction coefficient is stable with little changes-at the stable film lubrication stage. After $1000 \mathrm{~s}$, the friction coefficient appears subtle rising tendency, which is because that with the deepening wearing process, the friction surface temperature rises, which causes water evaporation and the lubrication film is absorbed and destroyed. Once the stable lubricating state is destroyed, the system will reconstruct new lubrication film. Only the reconstruction speed of the lubrication films is faster than the wearing and absorption speed can it maintain the film lubrication of the friction surface. The impregnated metallic antimony has high melting point and high hardness, which will increase the wear resistance of the materials and delay the absorption speed. So it is conducive to the reconstruction and the maintenance of the lubrication films under high temperature. This also gives full play to the sound wear resistance of lubricating performance of the antimony/graphite composites under high temperature. In Fig. 4, after 1000 s, the friction coefficients of every sample do not witness a large rise, which indicates that the speed of fast lubrication film is much faster than absorption and destroy speed, but the whole process still maintains the stable wearing conditions of film lubrication.

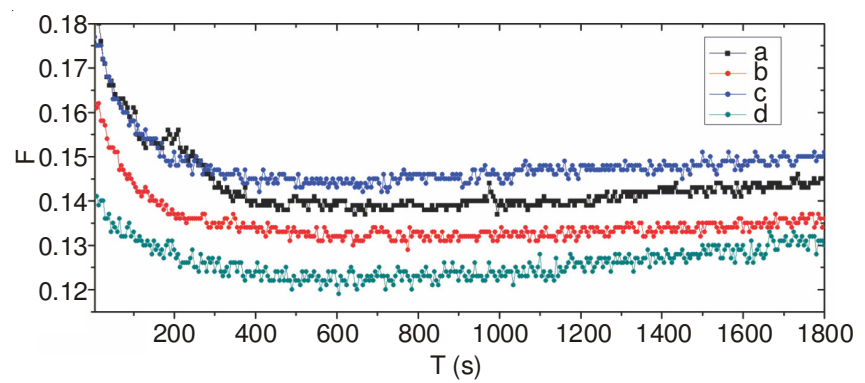

Fig. 4. Friction coefficients of the graphite/antimony composites against the $45 \#$ steel test ring

Fig. 5 shows the SEM morphologies of the samples after wearing. It can be seen that there has some apparent scratches and separate grooves in sample c. On the other hand, the surface of the other three samples is rather smooth, which indicates that a relatively sound lubrication film is created during the wearing process. In addition, the local holes without impregnation and sharp metallic antimony particles before wearing have been grinded with no large bulks of particles dropping off. Except the different distribution of the metallic antimony, there is a strong agreement in the surface characteristics in every sample after wearing.

\section{Conclusion}

Through impregnating the metallic antimony, the strength, hardness and wear resistance of porous graphite materials have been greatly improved, representing an ideal mechanical sealing material under high temperature and heavy load conditions in place of impregnated resin sealing materials. For a long time, the antimony/graphite materials made by the enterprises 

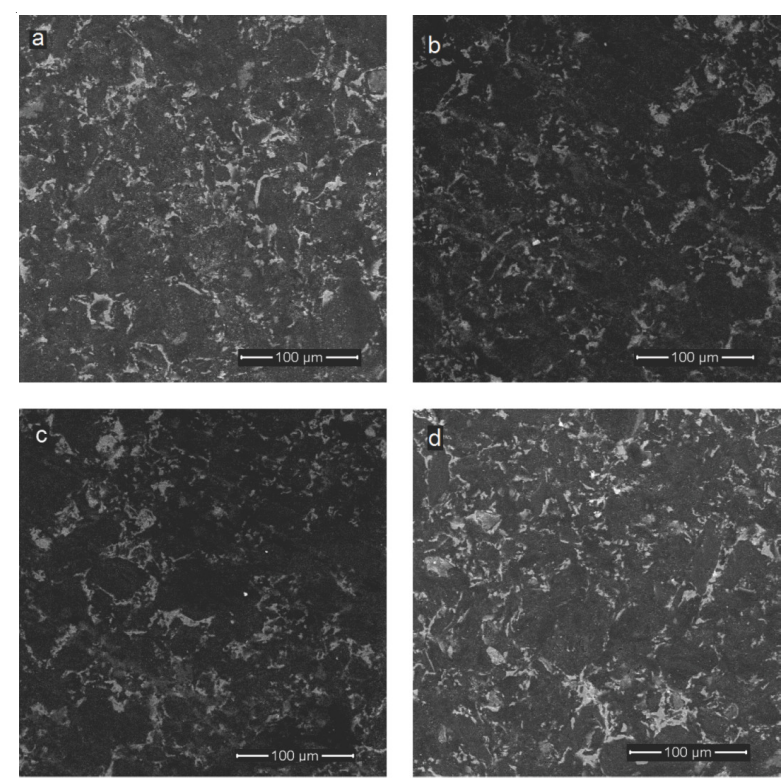

Fig. 5. SEM morphologies of surfaces of the graphite/antimony composites under dry sliding friction

represented by Germany, US and Japan take lead in the world and the same products in other countries still lag behind in terms of mechanical performance and friction and wear performance. The antimony/graphite composites made by the authors has reached the international advanced level-the density is $2.40 \mathrm{~g} / \mathrm{cm}^{3}$, the compression strength is $285 \mathrm{MPa}$, the flexural strength is $90 \mathrm{MPa}$, the Shore hardness is 102.5 Hs and the friction coefficient ranges from 0.12 to 0.14 . Moreover, according to the results of the industrial application, the service life of the material made by the authors is more than 20000 hours, which is longer than the similar material from Japan and US (16000-18000 h), only slightly less than the similar material from Germany (22000-25000 h).

The results of EDS show that the elements and structure of graphite/antimony composites are basically the same. Except the matrix carbon, the main elements are antimony, $\mathrm{Si}$, sulfur as well as other secondary elements like Fe, $\mathrm{Al}$ and $\mathrm{K}$. The relative content of antimony is $72-87 \%$, which greatly increase the density and wear resistance of the materials. The study of microstructure shows that the metal phase of antimony is evenly distributed in porous materials and basically forms the network structure with long-distance connection. The antimony/graphite composites made by the author has the largest number of impregnation with dense structure, but there are a few large size aggregate particles, forming a few holes without impregnation. In the initial stage of friction and wear experiment, the lubrication film is quickly created and it begins to absorb with the rising of temperature on the friction surface. However, the sound wear resistance of the antimony delays the absorption speed, so the reconstruction speed of lubrication film is much faster than its destroying speed, reforming the stable film lubrication state.

\section{ACKNOWLEDGEMENTS}

The authors acknowledged the financial support by the Natural Science Foundation of China for Innovative Research Group (No.51221462), the Postdoctoral Science Foundation of Jiangsu Province of China (No.1302035C), the Natural Science Foundation of Jiangsu Province of China (No. BK2013222), the Major Scientific and Technological support for Innovation Projects of Jiangsu Province of China (No. BY2011122).

\section{REFERENCES}

1. T. Etter, M. Papakyriacou, P. Schulz and P.J. Uggowitzer, Carbon, 41, 1017 (2003).

2. Q.L. Lin, R.G. Zheng and P.H. Tian, Polym. Test., 29, 537 (2010).

3. N. Cunningham, M. Lefevre, J.P. Dodelet, Y. Thomas and S. Pelletier, Carbon, 43, 3054 (2005).

4. T. Etter, J. Kuebler, T. Frey, P. Schulz, J.F. Löffler and P.J. Uggowitzer, Mater. Sci. Eng. A, 386, 61 (2004).

5. G.P. Khanra, S. Girikumar, D. Gangadhar, D.K. Mishra, T.T. Saravanan, S. Dineshraj and S.C. Sharma, Mater. Sci. Forum, 710, 326 (2012).

6. C.P. Lungu and K. Iwasaki, Vacuum, 66, 385 (2002).

7. M.P. Afonin and A.V. Boiko, Powder Metall. Metal Ceram., 44, 84 (2005).

8. Y. F. Hu, Y. J. Zhang and Y. S Sheng, Electric Power, 39, 91(2006).

9. Y.F. Hu, Q.L. Wang and Q. Liu, J. China Univ. Mining Technol., 39, 223 (2010).

10. Y. F. Hu, Q. Liu and W. W. Jiang, J. China Coal Soc., 36, 351 (2011).

11. H.W. Chang and R.M. Rusank, Wear, 80, 7 (1982).

12. E. Fiter and L.M. Manocha, Carbon Reinforcements and Carbon/Carbon Composites, Springer, Berlin, pp. 276-277 (2012).

13. M.Z. Yi, Y.C. Ge and B.Y. Huang, The Chinese J. Nonf. Met., 16, 929 (2006).

14. M.Z. Yi, Y.C. Ge and Y.L. Feng, Tribology, 24, 235 (2004).

15. O.P. Khatri and S.K. Biswas, Surf. Sci., 600, 4399 (2006).

16. A. Morina and A. Nevill, Tribology Int., 40,1696 (2007).

17. J.H. Jia, J.M. Chen, H.D. Zhou, J.- Wang and H. Zhou, Tribol. Int., 37, 423 (2004).

18. H. Goto and K. Uchijo, Tribol. Trans., 48, 548 (2005).

19. H. Goto and C.V. Suciu, Proceedings of the ASME/STLE International Joint Tribology Conference, JPN, pp. 71-73 (2009).

20. R.K. Goyal and M. Yadav, J. Appl. Polym. Sci., 127, 3186 (2013).

21. B.K. Prasad, Can. Metal. Qua., 47, 495 (2008).

22. R.R. Pakston, The Production of Self-Lubricative Carbon Produce Used in Machine, Pure Carbon Co. New York (1999).

23. H. Hirani and S.S. Goilkar, Wear, 266, 1141 (2009).

24. F. Akhlaghi and A. Zare-Bidaki, Wear, 266, 37 (2009).

25. M. Roe and A.A. Torrance, Tribol. Int., 41, 1002 (2008).

26. Q.L. Wang, Y.F. Hu and M. He, J. China Univ. Mining Technol., 18, 441 (2008). 